\title{
Plasma based platinum nanoaggregates deposited on carbon nanofibers improve fuel cell efficiency
}

\author{
Amaël Caillard, ${ }^{\text {a),b) }}$ Christine Charles, ${ }^{\text {a),c) }}$ and Rod Boswell \\ Space Plasma, Power, and Propulsion group (SP3), Research School of Physical Sciences and Engineering, \\ The Australian National University, Canberra, ACT 0200, Australia \\ Pascal Brault \\ Groupe de Recherche sur l'Energétique des Milieux Ionisés (GREMI), UMR 6606, \\ Université d'Orléans-CNRS Polytech'Orléans, BP 6744, F-45067 Orléans Cedex 2, France \\ Christophe Coutanceau \\ Laboratoire de Catalyse en Chimie Organique (LACCO), UMR 6503, Université de Poitiers-CNRS, \\ F-86022 Poitiers, France
}

(Received 1 March 2007; accepted 8 May 2007; published online 1 June 2007)

\begin{abstract}
Improved platinum catalytic utilization has been achieved by creating an open support structure based on aligned carbon nanofibers (CNFs) attached to carbon loaded carbon cloth electrodes [known as gas diffusion layer (GDL)]. The nickel catalyst used to initiate the CNFs growth; the CNFs themselves and the $5 \mathrm{~nm}$ Pt nanoaggregates were deposited sequentially in the same low pressure plasma reactor. This oriented catalyst structure was incorporated into a membrane electrode assembly and tested with and without CNFs and on carbon paper or GDL. The performance of the fuel cells based on CNFs and GDL was better over the entire range of operating current. (C) 2007 American Institute of Physics. [DOI: 10.1063/1.2745210]
\end{abstract}

The proton exchange membrane fuel cell (PEMFC) offers attractive mass market applications, primarily in personal transport aimed at reducing urban pollution. Its efficiency strongly depends on the membrane-electrode assembly and one of the challenges in its commercialization is the high cost of noble metals used as catalyst (e.g., Pt) in the electrodes. Increasing the Pt utilization efficiency in order to decrease the Pt amount in the catalytic layer has been one of the major concerns during the past decade. ${ }^{1}$ However, even with the most advanced conventional electrodes where small 2-3 nm Pt nanoparticles are dispersed in a porous carbon particle skeleton flooded in a conduction proton solution (Nafion®), Pt utilization remains low.

Carbon nanofibers or carbon nanotubes have already been proposed as a replacement for traditional carbon particle powders in PEMFC electrode because of their high electrical conductivity, unique surface structure, large surface area, and chemical inertia. ${ }^{2}$ These nanocomposites have usually been used in powders mixed with Nafion ${ }^{\circledR}$ and spread on electronic conductive supports such as carbon cloth or carbon paper. ${ }^{3-6}$ In this case, the results did not show many advantages over conventional carbon particle powders because this resulting configuration presented similar limitations to those of the conventional designs. The carbon nanofiber/carbon nanotubes (CNF/CNTs) were isolated from electron pathways due to the Nafion ${ }^{\circledR}$ coverage leading to a low electronic conductivity; ${ }^{7}$ the convoluted electrode architecture resulted in poor gas diffusivity and access to the Pt catalyst. The feasibility of a fuel cell using carbon nanotubes directly grown on electrodes has been recently demonstrated using silica gel to catalyze CNT growth ${ }^{8,9}$ or using a process of electrodeposition of Pt on CNTs grown by chemical vapor deposition (CVD) on carbon paper after an initial elec-

\footnotetext{
a) Authors to whom correspodence should be addressed.

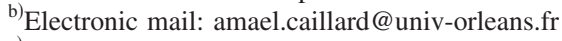

${ }^{c)}$ Electronic mail: christine.charles@ anu.edu.au
}

trodeposition of Co catalyst. ${ }^{7,10,11}$ Unfortunately, the subsequent membrane electrode assembly (MEA) performance remained low, possibly as a result of the large diameter $(25 \mathrm{~nm})$ of the Pt particle size.

In earlier work, we reported the role of sputter plasma deposited Pt on carbon electrodes as a technique for improving PEMFC efficiency. ${ }^{12-14}$ For much lower Pt loadings, a similar MEA voltage current curve was obtained but only for low fuel flow rates. Nevertheless, it was demonstrated that plasma sputtering of catalyst is a suitable method for obtaining efficient use of the catalyst. Aligned CNT growth on carbon microfibers has been recently reported by using CVD enhanced by dc plasma. ${ }^{15}$ Although several papers report on the use of plasma processes either for CNT growth or Pt deposition, most of them require both plasma and electrochemistry processes, which are difficult to combine in the objective of an industrial production of fuel cells. Nevertheless, $\mathrm{Pd} / \mathrm{C}$ and $\mathrm{Pt} / \mathrm{C}$ nanostructures have recently been grown on $\mathrm{Si}$ and carbon cloth using a combination of iron evaporation, microwave plasma enhanced CVD, and sputtering methods, ${ }^{16,17}$ but no MEA assembly or performance were reported.

The present experiments aim to combine the plasma growth of carbon aligned nanofibers with plasma sputtering growth of platinum nanoaggregates to create an oriented catalyst layer $^{18,19}$ that is sufficiently porous to allow a free flow of fuel gas while exposing the fuel to an effective amount of catalyst. To achieve this aim a low pressure high density radio frequency plasma discharge system shown in Fig. 1 has been constructed that is based on the helicon plasma source which can operate at a variety of different gas pressures. In order to allow a comparison of different techniques, four different types of catalytic layers have been deposited: two on carbon loaded carbon cloth and two on carbon paper, of which one each had additional carbon nanofibers deposited. Subsequently, all four were subjected to the same plasma deposition of the Pt catalyst. 


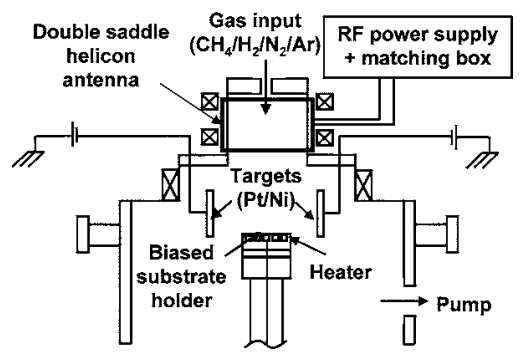

FIG. 1. Schematic of the Helicon PECVD reactor "southern cross."

A conventional fuel cell electrode consists GDL (Pt/C catalyst and Nafion ${ }^{\circledR}$ on carbon paper). In the present procedure, three consecutive plasma deposition steps were carried out in the helicon reactor: the nickel catalyst used to initiate the growth of the $35 \mathrm{~nm}$ diameter $2 \mu \mathrm{m}$ long CNFs, the CNFs themselves, and the $5 \mathrm{~nm}$ nanoclusters of platinum. The electrode holder is placed in the center of the plasma diffusion chamber which is contiguously attached to the low pressure high density radio frequency $(13.56 \mathrm{MHz})$ helicon plasma source, about $10 \mathrm{~cm}$ above the electrode holder. The $\mathrm{Pt}$ and Ni targets are positioned between the source and the $72 \mathrm{~mm}$ diameter electrode holder on either side of the "bright dress shape" plasma.

The 25-35 nm Ni catalyst clusters are grown on two of the four electrodes by using a $500 \mathrm{~W}, 5 \mathrm{mTorr}$ argon plasma, to sputter a $-300 \mathrm{~V}$ biased Ni target. Subsequent to the Ni catalyst deposition, the thermal substrate temperature induced by a spiral heater is gradually increased to $400{ }^{\circ} \mathrm{C}$ over a period of $15 \mathrm{~min}$ in secondary vacuum (below 5 $\left.\times 10^{-6} \mathrm{mbar}\right)$. The well aligned $2 \mu \mathrm{m}$ long CNFs are subsequently grown on $-100 \mathrm{~V}$ biased substrate at $400^{\circ}$ for $45 \mathrm{~min}$ in a $5 \mathrm{mTorr} \mathrm{CH}_{4} / \mathrm{H}_{2}$ plasma (flow rate ratio of 1:4). For the final Pt catalyst deposition step on the four electrodes, an argon plasma of density about $n=10^{11} \mathrm{~cm}^{-3}$ operating at a pressure of $5 \mathrm{mTorr}$ is used to sputter a $-300 \mathrm{~V}$ biased Pt target and deposit the 3-10 nm in size Pt nanoparticles. A sputtering time of $4 \mathrm{~min}$ is used, resulting in a platinum loading of $0.02 \mathrm{mg}_{\mathrm{Pt}} \mathrm{cm}^{-2}$. A schematic of the four electrode structures is shown in Figs. 2(a)-2(d): (a) Pt/carbon paper, (b) Pt/CNFs/carbon paper, (c) Pt/GDL, and (d) Pt/ $\mathrm{CNF} / \mathrm{GDL}$. The synthesis carbon nanofibers were characterized using scanning electron microscopy (Hitachi, S4500) and a transmission electron microscopy (Hitachi, H7100FA).

The scanning electron microscopy (SEM) photographs of two of these four synthesized electrodes [(b) Pt/CNFs/ carbon paper and (d) Pt/CNFs/GDL electrodes], prior to the

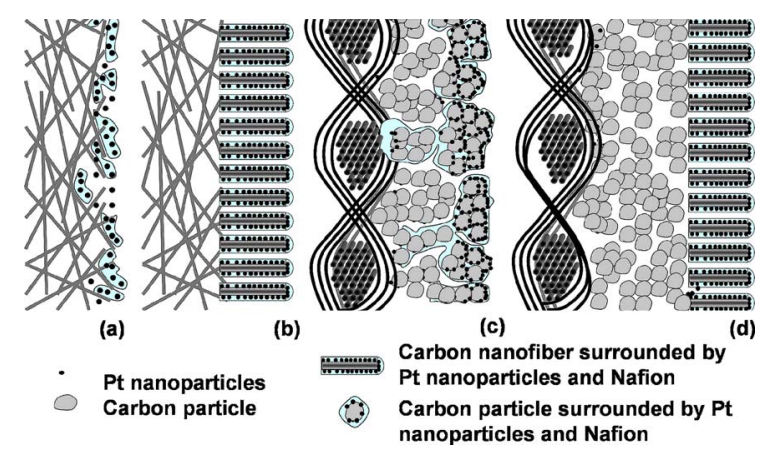

FIG. 2. (Color online) Schematic of the four physically prepared electrodes: (a) $\mathrm{Pt} /$ carbon paper, (b) $\mathrm{Pt} / \mathrm{CNFs} /$ carbon paper, (c) $\mathrm{Pt} / \mathrm{GDL}$, and (d) $\mathrm{Pt} / \mathrm{CNF} / \mathrm{GDL}$.

FIG. 4. TEM images of a CNF (a) before and (b) after Pt sputtering.
Pt/CNFs/GDL.
Downloaded 14 Nov 2007 to 130.56.17.217. Redistribution subject to AIP license or copyright, see http://apl.aip.org/apl/copyright.jsp
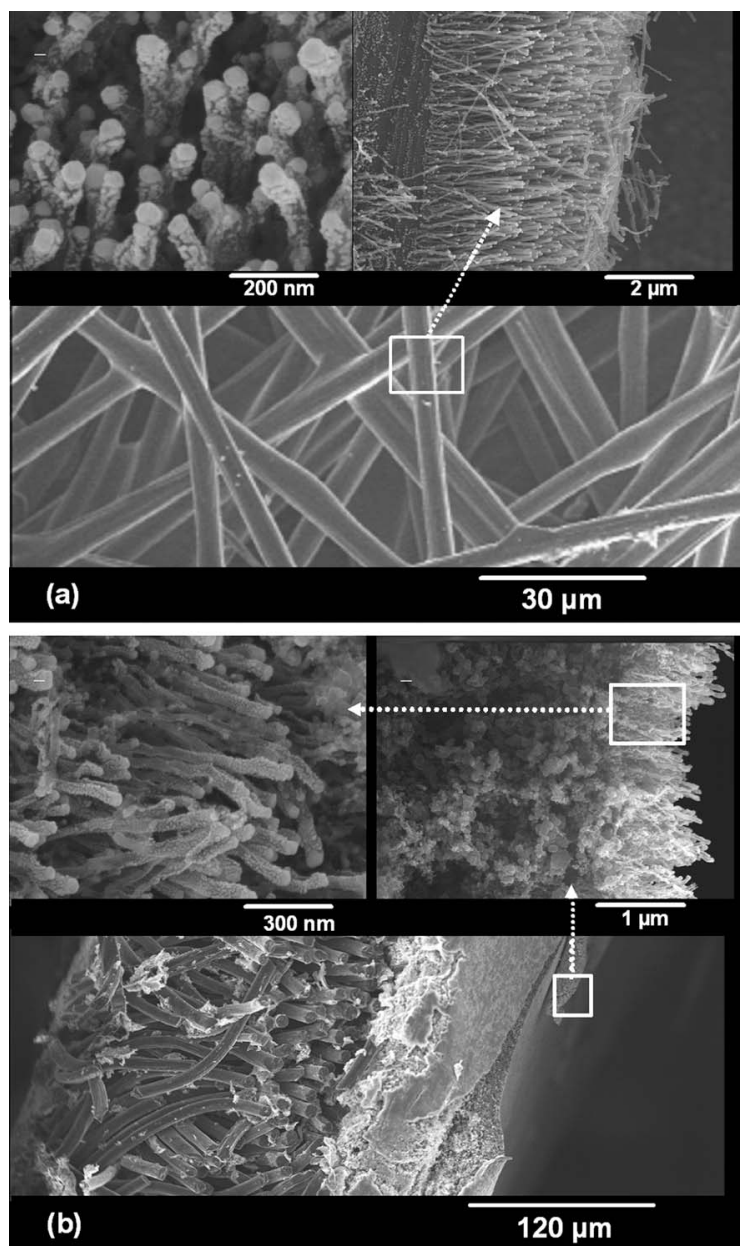

FIG. 3. SEM images of CNFs based electrodes on (a) carbon paper and on (b) GDL, respectively, corresponding to the schematics of electrode (b) and electrode (d) shown on Fig. 2.

final coating with Nafion®, are shown on Figs. 3(a) and 3(b), respectively.

Figure 4 shows the transmission electron microscopy (TEM) pictures of the upper end of a CNF (a) before and (b) after platinum deposition. The presence of the $\mathrm{Ni}$ catalyst at the tip of the CNF suggests a "tip" growth model. ${ }^{20}$ Most of the CNFs have a narrow statistical distribution of diameters that peak at around $35 \mathrm{~nm}$. At the end of the process, each $\mathrm{Ni}$ particle is surrounded by a thin carbon layer on the face exposed to the $\mathrm{CH}_{4} / \mathrm{H}_{2}$ plasma, an important advantage for fuel cell application. This carbon film prevents both nickel

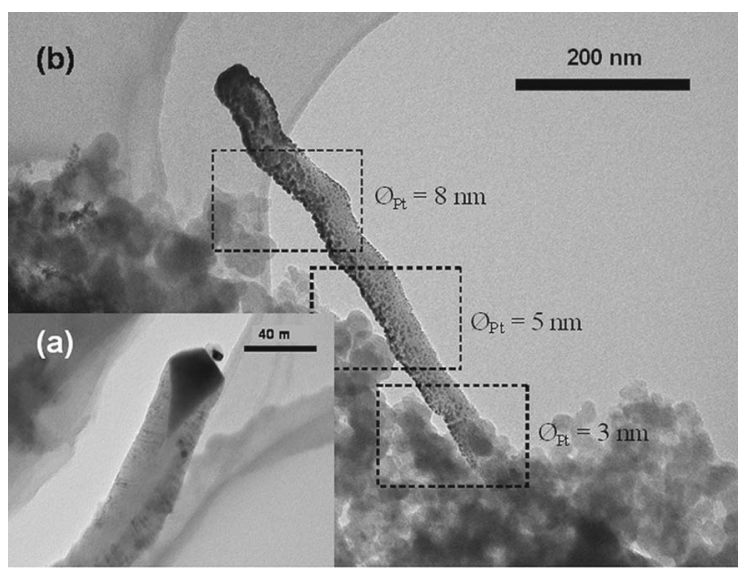




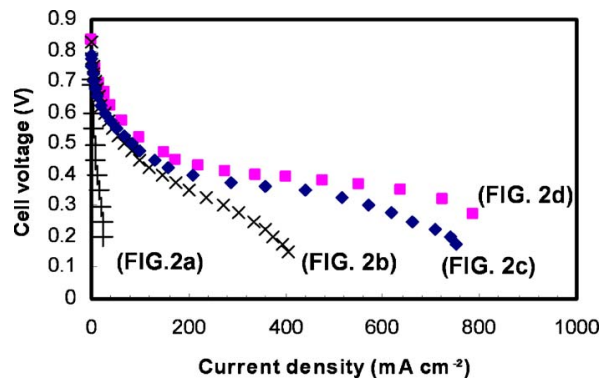

FIG. 5. (Color online) Cell voltage $E$ vs current density $j$ curves for the four prepared electrodes schematized in Fig. 2: (a) Pt/carbon paper, (b) Pt/CNFs/ carbon paper, (c) Pt/GDL, and (d) Pt/CNFs/GDL. The PEMFC surface area is $5 \mathrm{~cm}^{2}$ and the Pt loading is $0.02 \mathrm{mg}_{\mathrm{Pt}} \mathrm{cm}^{-2}$. $\left[P_{\mathrm{H}_{2}}=P_{\mathrm{O}_{2}}=3\right.$ bars; $\mathrm{H}_{2}$ flow $=\mathrm{O}_{2}$ flow $=100 \mathrm{SCCM}$ (SCCM denotes cubic centimeter per minute at JTP); $T_{\text {cell }}=80^{\circ} \mathrm{C}$, membrane Nafion $\left.{ }^{\circledR} 115\right]$. Nafion ${ }^{\circledR}$ loading of $1 \mathrm{mg} \mathrm{cm}^{-2}$ on cathode and $1.5 \mathrm{mg} \mathrm{cm}^{-2}$ on anode. MEA hot pressing: $130{ }^{\circ} \mathrm{C}$ for $120 \mathrm{~s}$ under a pressure of $40 \mathrm{~kg} \mathrm{~cm}^{-2}$.

dissolution in the fuel cell's corrosive environment and nickel conduction throughout the hydrated membrane, which would result in closing proton conduction channels. Figure 4(b) shows that the $2 \mu \mathrm{m}$ long CNF is covered by well dispersed Pt nanoparticles all along its length, yielding efficient utilization of the large surface area of the CNFs. The diameter distribution of these nanoparticles decreases near the base of the CNFs that is attached to the carbon support: $8 / 5 / 3 \mathrm{~nm}$ diameter at $100 / 250 / 600 \mathrm{~nm}$ from CNFs carpet surface. The $\mathrm{Pt}$ nanoparticles density is higher at the electrode-membrane interface where the $\mathrm{Pt}$ catalyst is the most active. ${ }^{21}$ Previous studies by electron microscopy of the plasma sputter-deposition of Pt onto the GDL without CNFs [e.g., electrode (c)] have shown the formation of a dense clustering layer at the surface of the catalyst layer. Even if Rutherford backscattering spectroscopy analysis on Pt catalyzed GDL has shown that a small fraction of Pt atoms penetrate over a distance of $2 \mu \mathrm{m},{ }^{11}$ the Pt nanoclusters are not visible over the whole penetration distance from microscopy analysis. Here, the aligned CNF based carbon support [e.g., electrode (d)] prevents the formation of a dense clustering layer at the surface of the catalyst layer (except on the CNF tip). Pt deposition is clearly visible along the CNF from TEM micrographs, indicating that this oriented carbon layer promotes a deeper Pt penetration.

The four electrodes were successively tested on the cathode side of a MEA in a single $5 \mathrm{~cm}^{2}$ fuel cell test station (fuel cell store). Standard E-TEK electrodes with a Pt loading of $0.5 \mathrm{mg}_{\mathrm{Pt}} \mathrm{cm}^{-2}$ were used at the anode side and a commercial Nafion ${ }^{\circledR} 115$ membrane was used between the two electrodes. The MEA was hot pressed after a thin film of Nafion ${ }^{\circledR}, 5 \mathrm{wt} \%$ solution was spread onto the electrodes to assure proton access from the membrane to the Pt nanoparticles. The polarization curves corresponding to the four electrodes [(a)-(d)] are shown in Fig. 5. These results clearly show that the presence of the CNFs as catalyst support significantly improves the cell performance as a result of an increased catalytic surface area. Although the relative increase of performance with CNFs on carbon paper is drastic over the whole range of investigated current, the voltage is consistently lower than that obtained for the electrodes on carbon cloth with a GDL. According to Wang et al., ${ }^{7}$ the polytetrafluoroethylene PTFE particles present in the GDL contribute to its hydrophobicity and water evacuation in op- eration, whereas carbon paper wets easily preventing oxygen fuel from accessing the catalytic sites. Improvement of the cell with CNFs grown on GDL is more noticeable at higher current: at a current density of $600 \mathrm{~mA} \mathrm{~cm}^{-2}$, the achieved power densities are close to 170 and $210 \mathrm{~mW} \mathrm{~cm}^{-2}$ without and with CNFs, respectively. This indicates a lower cell resistance, hence higher electronic and protonic conductivities from the oriented catalyst layer based on aligned CNFs. Although the performance of the CNF based electrode is still lower than that of the conventional one $\left(400 \mathrm{~mW} \mathrm{~cm}^{-2}\right)$ for the same operating conditions, the Pt loading is much lower in the plasma synthesised electrode $\left(0.02 \mathrm{mg}_{\mathrm{Pt}} \mathrm{cm}^{-2}\right)$ than in a conventional electrode $\left(0.5 \mathrm{mg}_{\mathrm{Pt}} \mathrm{cm}^{-2}\right)$, indicating that the ratio of platinum used in this CNF based active layer is much higher than that of the conventional one.

Plasma techniques have been used to grow vertically aligned CNFs and to deposit nanoaggregate platinum along their length of $2 \mu \mathrm{m}$, thereby significantly increasing the fuel catalysis and usage. Tests of MEAs show that the best results were obtained for CNFs grown on GDLs consisting of carbon black and PTFE particles to provide adequate hydrophobicity and water evacuation during operation.

One of the authors (A.C.) gratefully acknowledges ARC Australian Research Network for Advanced Materials, CNRS (GDR-I "Plasmas") and ANU for financial support.

${ }^{1}$ R. Borgward, Transp. Res. D 6, 199 (2001).

${ }^{2}$ K. Lee, J. Zhang, H. Wang, and D. P. Wilkinson, J. Appl. Electrochem. 36, 507 (2006).

${ }^{3}$ W. Li, C. Liang, J. Qiu, W. Zhou, H. Han, Z. Wei, G. Sun, and Q. Xin, Carbon 40, 787 (2002).

${ }^{4}$ W. Li, C. Liang, W. Zhou, J. Qiu, Z. Zhou, G. Sun, and Q. Xin, J. Phys. Chem. B 107, 6292 (2003).

${ }^{5}$ E. S. Steigerwalt, G. A. Deluga, D. E. Cliffel, and C. M. Lukehart, J. Phys. Chem. B 105, 8097 (2001).

${ }^{6}$ E. Steigerwalt, G. A. Deluga, and C. M. Lukehart, J. Phys. Chem. B 106, 760 (2002).

${ }^{7}$ C. Wang, M. Waje, X. Wang, J. M. Tang, R. C. Haddon, and Y. Yan, Nano Lett. 4, 345 (2004).

${ }^{8}$ X. Sun, R. Li, D. Villiers, J. P. Dodelet, and S. Désilets, Chem. Phys. Lett. 379, 99 (2003).

${ }^{9}$ X. Sun, R. Li, B. Stanfield, J. P. Dodelet, and S. Désilets, Chem. Phys. Lett. 394, 266 (2004).

${ }^{10}$ M. M. Waje, X. Wang, W. Li, and Y. Yan, Nanotechnology 16, 395 (2005).

${ }^{11}$ X. Wang, M. Waje, and Y. Yan, Electrochem. Solid-State Lett. 8, 42 (2005).

${ }^{12}$ P. Brault, A. Caillard, A.-L. Thomann, J. Mathias, C. Charles, R. W. Boswell, S. Escribano, J. Durand, and T. Sauvage, J. Phys. D 37, 3419 (2004).

${ }^{13}$ A. Caillard, P. Brault, J. Mathias, C. Charles, and R. W. Boswell, Surf. Coat. Technol. 200, 391 (2005).

${ }^{14}$ P. Brault, S. Roualdès, A. Caillard, A.-L. Thomann, J. Mathias, J. Durand, C. Coutanceau, J.-M. Léger, C. Charles, and R. Boswell, Eur. Phys. J.: Appl. Phys. 34, 151 (2006).

${ }^{15}$ L.-H. Chen, J. F. Aubuchon, I.-C. Chen, C. Daraio, X.-R. Ye, A. Gapin, S. Jin, and C. M. Wang, Appl. Phys. Lett. 88, 033103 (2006).

${ }^{16}$ C.-L. Sun, L.-C. Chen, M.-C. Su, L.-S. Hong, O. Chyan, C.-Y. Hsu, K.-H. Chen, T.-F. Chang, and L. Chang, Chem. Mater. 17, 3749 (2005).

${ }^{17}$ C.-C. Chen, C. F. Chen, C.-H. Hsu, and I.-H. Li, Diamond Relat. Mater. 14, 770 (2005).

${ }^{18}$ E. Middelman, Fuel Cells Bull. 9 (2002).

${ }^{19}$ C. Y. Du, X. Q. Cheng, T. Yang, G. P. Yin, and P. F. Shi, Electrochem. Commun. 7, 1411 (2005).

${ }^{20}$ R. T. K. Baker, M. A. Barber, P. S. Harris, F. S. Feates, and R. J. Waite, J. Catal. 26, 51 (1972).

${ }^{21}$ O. Antoine, Y. Bultel, P. Ozil, and R. Durand, Electrochim. Acta 45, 4493 (2000). 